\title{
The predictive role of color doppler sonography in evaluating hypoxia and acidosis in intrauterine growth restriction fetuses: correlation with arterial blood gas analysis
}

\author{
Triptpal Kaur, Reema Kumar Bhatt*
}

Department of Obstetrics and Gynecology, Army Hospital Research and Referral Centre, New Delhi, India

\author{
Received: 28 December 2019 \\ Revised: 27 January 2020 \\ Accepted: 01 February 2020 \\ *Correspondence: \\ Dr. Reema Kumar Bhatt, \\ E-mail: reemakamalbhatt@yahoo.co.in
}

Copyright: (c) the author(s), publisher and licensee Medip Academy. This is an open-access article distributed under the terms of the Creative Commons Attribution Non-Commercial License, which permits unrestricted non-commercial use, distribution, and reproduction in any medium, provided the original work is properly cited.

\begin{abstract}
Background: Doppler is an ultrasound technique allowing non-invasive measurement of artery blood flow velocities. Objective of this study was to evaluate the role of umbilical artery (UA) and middle cerebral artery (MCA) Doppler study in predicting fetal hypoxia and acidosis in IUGR fetus and a population subjected to hematologic fluctuations. Methods: In this study 100 subjects with IUGR fetuses was evaluated for comparison of Doppler sonography analysis of fetal middle cerebral arteries and umbilical arteries and cord blood samples (pCO2, pO2) that was collected at the time of delivery.

Results: Among the 100 subjects (between 28-32 gestational week) of IUGR showed a high risk of hypoxia and acidosis type condition. The observations were recorded in terms of MCA/UA ratio, the abnormal MCA/UA ratio was observed in significant $(\mathrm{p}<0.05)$ number of patients growth restricted fetuses $(n=96)$, as compared to normal. There is a direct correlation found in the $\mathrm{pH}$ and $\mathrm{pCO}_{2}$ values. The results of arterial blood gases with respect to $\mathrm{pH}$ were found to be less than $7.3 \pm 1.6$ in 96 subjects with abnormal MCA/UA ratio as compared to normal, that relates to the increase in the relative $\mathrm{pCO}_{2}(61.66 \%)$ [Acid increase] and decrease in $\mathrm{pO}_{2}$ arterial gases (Hpoxia increase).

Conclusions: The study provides an insight that shows IUGR fetuses have a relatively higher risk of hypoxia (less oxygen) and acidosis (low $\mathrm{pH}$ and high $\mathrm{pCO}_{2}$ ), showed the most important determinants variations.
\end{abstract}

Keywords: Acidosis, Doppler sonography, Fetus, Hypoxia, Intrauterine growth reduction

\section{INTRODUCTION}

Intrauterine growth restriction (IUGR) is a clinical event frequently associated with the with chromosomal and congenital malformations with large number of poor perinatal outcomes. In the current obstetrics practice, the American College of obstetricians and gynecologists also considers IUGR with frequently encountered complex situations. ${ }^{1}$ The most commonly used definition of IUGR equates with the gestational age of the fetus, i.e. "the estimated fetal weight is less than $10^{\text {th }}$ percentile, and the specific cut off point based on gestational age. ${ }^{2}$ There is now a suggestion to use an extended definition of fetal growth restriction (FGR) by a Delphi procedure which involves the incorporation of different Doppler parameters that are considered better indicators to diagnose growth restriction and to differentiate small for gestational age (SGA) from FGR. ${ }^{3}$

It is generally prevalent in $4-10 \%$ neonates. Mounting issues includes (a) maternal factors such as poor nutrition, hypertension, thrombophilia (b) placental factors such as blood flow, amount of oxygen and nutrition to the fetus throughout the pregnancy and cell 
death; (c) fetal factors including malformations. It also has a significant association with fetal and neonatal mortality and morbidity and elicits wide range of obstetric adverse events like prematurity and cerebral palsy. ${ }^{4,5}$ The presence of hypoxia in the fetus with growth restrictions becomes important in taking decision regarding timing of delivery. ${ }^{6}$

Ultrasonography is widely used technique during pregnancy to evaluate pregnancy age, fetal size through serial biometric measurement and amniotic fluid index. ${ }^{7}$ In addition use of Doppler ultrasound is an important component in clinical practice to decide on the severity of IUGR and this tool is an essential component on deciding the decision on timing of delivery. ${ }^{8}$ Hypoxia could be estimated with the array of parameters such as pulsatility and resistance index (PI and RI) of the umbilical artery, uterine and middle cerebral artery (MCA), the Swave/isovolumetric and the A-wave (SIA) index of ductus venosus (DV). ${ }^{9-11}$ Therefore, in this present study, we herein aimed to compare fetal MCA and umbilical artery color Doppler ultrasound association with hypoxia and acidosis in pregnancies complicated by IUGR.

\section{METHODS}

In the prospective-analytical study, 100 cases of high-risk pregnancies with IUGR were recruited in the department of obstetrics and gynecology, tertiary care hospital from October 2015 to September 2017. The color Doppler results for middle cerebral arteries (MCA) and umbilical were studied in pregnancies between 28 -40 weeks, clinically suspected IUGR due to chronic placental insufficiency and ultrasonographically proven singleton pregnancies. The cases with multiple pregnancies, congenital anomalous fetuses, symmetrical IUGR and IUGR with TORCH infections were generally excluded from the study. This study was approved by the ethical committee of our hospital.

In this study, all the examinations were performed using GE LOGIC 3 EXPERT scanner with $3.5 \mathrm{MHz}$ transducer. The scanning was done to measure the Biparietal Diameter (BPD), Head Circumference (HC), Abdominal Circumference (AC) in these neonates, femur length (FL), amniotic fluid volume fetal weight measurement (EFW) to diagnose IUGR. It was diagnosed when "the estimated fetal growth weight or AC less than $10^{\text {th }}$ percentile at that gestational age. All IUGR fetuses were subjected to umbilical artery and MCA Dopplers.

\section{Measurements optimization}

During the examination, the women were in a semi recumbent position with the head and chest slightly elevated. The umbilical artery doppler indices were estimated on a free loop of cord. The waveforms of good quality were collected and analyzed in the absence of fetal breathing movements with $\mathrm{n}=3$ repeat observations.
For measurements of the middle cerebral artery indices, an axial view of the fetal head was obtained at the level of the cerebral peduncles. Color Doppler was used to visualize the circle of Willis. The Doppler sample volume was placed within $1 \mathrm{~cm}$ of the origin of the middle cerebral artery that was easily identified as a major branch running in antero-lateral direction from the circle of Willis towards the lateral edge of the orbit. While angle of correction is not necessary when measuring the middle cerebral artery pulsatility index (PI), peak systolic velocity measurement should use angle correction and the angle of incidence should be $<30^{\circ}$; optimally as close to $0^{\circ}$ as possible.

For the waveform analysis, maximum and minimum values of the velocity waveforms on the frozen image were measured by use of electronic calipers of the machine. The Pourcelot resistance index (systolediastole/diastole) was calculated. To analyze umbilical gas and acid base, cord blood was taken from umbilical artery, collected immediately after birth via heparin syringe aspirations. The results were obtained to understudy the variables, $\mathrm{pCO}_{2}, \mathrm{pO}_{2}$, and $\mathrm{pH}$ in IUGR subjects.

The inclusion criteria included clinically suspected IUGR due to chronic placental insufficiency and singleton pregnancies. The exclusion criteria included multiple pregnancies, congenital anomalous fetuses, Symmetrical IUGR and IUGR with TORCH infections.

\section{Statistical analysis}

SPSS 17.0 statistical software was used for statistical evaluation. The results, outcomes stated in terms of frequency percentage, Mean \pm SEM with $p<0.05$ as meaningful probability.

\section{RESULTS}

In this study, 100 high risk pregnancy cases with IUGR between 28-40 weeks of gestation were selected. Out of 100 cases, the mean maternal age was ranged between 23-40 years, and highest numbers of cases were reported between the ages of 31-35 years. Out of 100 cases, $78 \%$ were Primigravida and $22 \%$ were Multi gravidae. Regarding gestational age, 56 subjects were in the gestational age between 28-32 weeks. The most common risk factor for high risk pregnancy was preeclampsia (70\%) and $\sim 10 \%$ had chronic hypertension and $\sim 5 \%$ had thrombophilia associated with growth restriction. The observations were recorded by Doppler sonography for the umbilical arteries (UmA) and middle cerebral arteries (MCA).

The data of Doppler sonography were correlated with the results for arterial blood gas parameters in terms of the PI ratio of MCA and $\mathrm{UA}$. The indices in MCA/ UA > 1 were considered to be the normal ratio $(n=6)$ while MCA/UA < 1 was considered abnormal $(\mathrm{n}=94)$. 
Subsequently, the study population of $\mathrm{n}=70$ subjects had PI of umbilical artery $>95^{\text {th }}$ percentile and PI of MCA < $5^{\text {th }}$ percentile, respectively for median selected gestational age. Furthermore, 12 subjects exhibited intermittent absent diastolic flow (IADF), 08 subjects displayed absent diastolic flow (ADF) and 10 subjects showed the reverse of diastolic flow (RDF) Doppler observations.
In the present study, the $\mathrm{pH}$ of UA was $7.32 \pm 0.12$ in subjects with PI of UA PI $<95$ percentile and PI of MCA $>5^{\text {th }}$ percentile respectively, for that gestational age and it decreased to $7.04 \pm 0.01$ in the patients with RDF. The results of arterial blood gases with respect to $\mathrm{pH}$ were

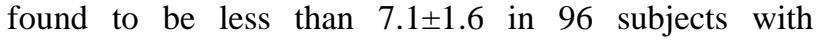
abnormal MCA/UA ratio as compared to normal with $7.33 \pm 2.56$ (Table 1).

Table 1: Arterial blood gas characteristics based on the MCA/UA ratio according to Doppler sonography.

\begin{tabular}{|lllll|}
\hline CPR (MCA/UA) ratio & $\mathrm{pH}$ & $\mathbf{p C O}_{2}$ & $\mathbf{p O}_{2}$ & \multicolumn{3}{c|}{ B/E } \\
\hline Abnormal MCA/UA $<1(\mathrm{n}=94)$ & $7.10 \pm 1.65$ & $49.34 \pm 2.76^{*}$ & $13.81 \pm 1.98^{*}$ & $-4 \pm 0.76^{*}$ \\
\hline Normal MCA/UA $>1(\mathrm{n}=6)$ & $7.33 \pm 0.56$ & $30.52 \pm 0.54$ & $16.51 \pm 0.34$ & $-2.04 \pm 0.86$ \\
\hline
\end{tabular}

*indicated the significant $(\mathrm{p}<0.05)$ change in the abnormal CPR ratio as compared to normal.

The analysis of arterial partial pressure of blood gases in correlation with the $\mathrm{pH}$ change, demonstrated that $\mathrm{pCO}_{2}$ was found to be significantly $(\mathrm{p}<0.05)$ increased in abnormal MCA/UA cases $(\mathrm{n}=96)$ with relative change of $61.66 \pm 3.76 \%$ as compared to normal results. In contrast, the $\mathrm{pO}_{2}$ showed drastic decrease in comparison to $\mathrm{pCO}_{2}$ increase with percentage change of $16.6 \pm 2.98 \%$ in observing less in abnormal MCA/UA cases as compared to normal. The relative change in the $\mathrm{pH}, \mathrm{pCO}_{2}$ in arterial blood exhibits acidosis type condition in the fetus with abnormal MCA/UA (Table 1).

Regarding, other observations recorded, it was found that fetal academia is absent in PI of umbilical artery $>95^{\text {th }}$ percentile and PI of MCA $<5^{\text {th }}$ percentile, respectively for that gestational age in contrast to absent and reversed diastolic flow. Out of 8 cases of ADF, 7 cases suffered from fetal academia and all the 10 cases of RDF suffered fetal academia.

The complications in neonates, out of 100 neonates, neonatal jaundice was highly prevalent $(36 \%)$ and these received intensive phototherapy. The other complications observed in the study were RDS (21\%), Fetal acidosis (17\%), and meconium aspirated syndrome (2\%) and mortality was observed in 3 neonates.

In this study, there was significant correlation between $\mathrm{MCA} / \mathrm{UA}$ ratio with respect to $\mathrm{pO}_{2}, \mathrm{pCO}_{2}, \mathrm{pH}$ was made that tend to cause hypoxia and acidosis type conditions.

\section{DISCUSSION}

In the complicated pregnancies, intrauterine growth restriction (IUGR) is a significant contributor to perinatal mortality and morbidity of the fetus. ${ }^{12}$ IUGR is frequently associated with significant medical complications that lead to the poor perinatal outcome. ${ }^{13}$ The preferred method for understanding, diagnosis and evaluating IUGR is ultra-sonographic examination including Doppler studies. Previous studies have also reported the benefits of Doppler sonography in pregnant women which showed that it plays a significant role in evaluating fetus growth condition and umbilical and middle cerebral arteries help in deciding the severity of growth restriction which aids in deciding the timing of delivery. ${ }^{14-17}$

In the present study, abnormality in UmA and MCA of IUGR pregnancies was observed. The results suggest that categorizing fetuses at risk with IUGR on the basis of MCA/UA Doppler and also doing an arterial blood analysis at birth $\left(\mathrm{pH}, \mathrm{pO}_{2}, \mathrm{pCO}_{2}\right)$ has important prognostic significance. The Doppler observations among the MCA/UA abnormal subjects were significantly different from normal subjects which co-related with blood gas analysis. Therefore, the fate of the fetus with IUGR can be predicted in this clinical study with inclusion of doppler's. The methodology adapted to study the process was safe in diagnosing growth restrictions in correlation with fetal hypoxia and acidosis. ${ }^{18}$

It is well reported that the $\mathrm{pH}$ and $\mathrm{pO}_{2}$ levels in the fetus with IUGR are lower as compared to the $\mathrm{pCO}_{2}$, which is substantially higher leading to hypoxia. Fetal hypoxia activates various physiological responses. When the fetus is under hypoxia, the fetal cardiovascular response includes modification of heart rate and redistribution of blood flow which allows cerebral arteries to dilate in order to preserve the blood flow to the brain. ${ }^{19}$ In the middle cerebral artery, the systolic to diastolic S/D ratio will decrease (due to an increase in diastolic flow) in the presence of chronic hypoxia in the fetus for maintaining homeostasis. ${ }^{20}$ The quantity of redistribution of the blood flow can be evidenced by Doppler ultrasound of the middle cerebral artery. This effect has been called "brain sparing effect" and is demonstrated by a lower value of the cerebro-placental ratio (PI of MCA/ UA) which becomes less than one in abnormal cases. ${ }^{21}$ The ratio of $\mathrm{MCA} / \mathrm{UA} \mathrm{PI}$ is quite accurate in the evaluation of fetuses with growth restriction. ${ }^{22}$

Fetal cord blood is used to correlate between the partial pressure of blood gases and $\mathrm{pH}$. The present study shows a significant correlation between color Doppler 
parameters and $\mathrm{pO}_{2}(\mathrm{mmHg})$ in umbilical artery (p $<0.005$ ). Further, previous studies are also comparable to our results indicating direct correlation between PI and $\mathrm{pO}_{2} \mathrm{pH}$ of UA, and an inverse correlation between the former and $\mathrm{pCO} 2$ of $\mathrm{UmA} .^{23}$ However, the negative correlation was observed between $\mathrm{pO}_{2}$ and $\mathrm{pH}$ of UmA. The current findings, likely to indicate regulatory mechanisms that are important in population with fetal IUGR in respect to changes in arterial oxygen content in fetal blood.

The leading cause of fetal morbidity and mortality in IUGR is long term hypoxia and acidosis. The standard surveillance procedures such as Doppler examinations of IUGR subjects provides the reliable data for the management of fetal complications. Nevertheless, the study also reflects the asymmetric patterns CPR ratio (MCA/UA) indicating the increase of $\mathrm{pCO}_{2}$ that lead to conditions like acidosis and decrease of $\mathrm{pO}_{2}$ raised hypoxia. Therefore, the CPR ratios must be measured during the prenatal monitoring of pregnancies with IUGR and should be an integral part of evaluation of growth restricted fetuses.

\section{CONCLUSION}

Absent and Reverse end diastolic flow Doppler has high sensitivity and specificity to predict fetal hypoxia and acidosis in IUGR pregnancies and therefore color Doppler ultrasonography has a definite role in monitoring IUGR fetuses and in decision making when to deliver.

\section{Funding: No funding sources}

Conflict of interest: None declared

Ethical approval: The study was approved by the Institutional Ethics Committee

\section{REFERENCES}

1. ACOG Practice Bulletin No. 204: Fetal Growth Restriction. Obstet Gynecol. 2019;133(2):e97-e109.

2. Battaglia FC, Lubchenko LO. A practical classification of newborn infants by weight and gestational age. J Pediatr. 1967;71:159-63.

3. Gordijn SJ, Beune IM, Thilaganathan B, Papageorghiou A, Baschat AA, Baker PN, et al. Consensus definition of fetal growth restriction: a Delphi procedure. Ultrasound Obstet Gynecol. 2016;48(3):333-9.

4. Anderson NH. Maternal and pathological pregnancy characteristics in customized birth weight centiles and identification of at-risk small-for-gestational-age infants: a retrospective cohort study. BJOG. 2012;119:848-56.

5. Gardosi J. Maternal and fetal risk factors for stillbirth: population-based study. BMJ. 2013;24.

6. Albu AR, Anca AF, Horhoianu VV, Horhoianu IA. Predictive factors for intrauterine growth restriction. J Med Life. 2014;7(2):165-71.
7. Ott WJ. The diagnosis of altered foetal growth. Obstet Gynecol Clin North Am. 1988;15:237-63.

8. Yagel S, Kivilevitch Z, Cohen SM, Valsky DV, Messing B, Shen O, Achiron R. The fetal venous system, Part II: ultrasound evaluation of the fetus with congenital venous system malformations or developing circulatory compromise. Ultrasound Obstet Gynecol. 2010;36(1):93-111.

9. Lakhkar BN, Rajagopal KV, Gourisankar PT. Doppler prediction of adverse perinatal outcome in PIH and IUGR. Ind J RadiolImag. 2006;16:109-16.

10. Simanaviciute D, Gudmundsson S. Fetal middle cerebral to uterine artery pulsatility index ratios in normal and pre-eclamptic pregnancies. Ultrasound Obstet Gynecol. 2006;28:794-801.

11. Shahinaj R, Manoku N, Kroi E, Tasha I. The value of the middle cerebral to umbilical artery Doppler ratio in the prediction of neonatal outcome in patient with preeclampsia and gestational hypertension. J Prenat Med. 2010;4(2):17-21.

12. Manning FA, Hill CM, Platt LD. Qualitative amniotic fluid volume determination by ultrasound: antepartum detection of intrauterine growth retardation. Am J Obstet Gynecol. 1981;139(3):2548.

13. Sankaran S, Kyle PM. Aetiology and pathogenesis of IUGR. Best Pract Res Clin Obstet Gynaecol. 2009;23(6):765-77.

14. Fardiazar Z, Atashkhouei S, Yosefzad Y, Goldust M, Torab R. Comparison of fetal middle cerebral arteries, umbilical and uterin artery color Doppler ultrasound with blood gas analysis in pregnancy complicated by IUGR. Iranian J Reprod Med. 2013;11(1):47.

15. Rhee E, Detti L, Mari G. Superior mesenteric artery flow velocity waveforms in small for gestational age fetuses. J Matern Fetal Med. 1998;7:120-3.

16. Baschat AA, Gembruch U, Reiss I, Gortner L, Weiner CP, Harman CR. Relationship between arterial and venous Doppler and perinatal outcome in fetal growth restriction. Ultrasound Obstet Gynecol. 2000;16:407-13.

17. Mari G, Abuhamad AZ, Uerpairojkit B, Martinez E, Copel JA. Blood flow velocity waveforms of the abdominal arteries in appropriate- and small-forgestational-age fetuses. Ultrasound Obstet Gynecol. 1995;6:15-8.

18. Sohn C, Meyberg G. Initial experiences with a new color technique: ultrasound angiography. Zentralbl Gynakol. 1995;117:90-6.

19. Salihagić-Kadić A, Medić M, Jugović D, Kos M, Latin V, Kušan Jukić M, et al. Fetal cerebrovascular response to chronic hypoxia-implications for the prevention of brain damage. J Maternal-Fetal Neonat Med. 2006;19(7):387-96.

20. King T, Parer J. The physiology of fetal heart rate patterns and perinatal asphyxia. J Perinat Neonat Nurs. 2000;14(3):19-39.

21. Yalti S, Oral Ö, Gürbüz B, Özden S, Atar F. Ratio of middle cerebral to umbilical artery blood velocity 
in preeclamptic and hypertensive women in the prediction of poor perinatal outcome. Ind J Med Res. 2004;120(1):44.

22. Banu AA. Doppler velocimetry in the umbilical and middle cerebral arteries in fetuses with intrauterine growth retardation or fetal distress. Fukuoka Igaku Zasshi. 1998;89(5):133-44.

23. $\mathrm{Xu} \mathrm{W}$, Yang Q, Zhu T. Colour Doppler ultrasonographic indices in predicting fetal hypoxia and acidosis Zhonghua $\mathrm{Fu}$ Chan KeZa Zhi. 1997;32(6):341-4

Cite this article as: Kaur T, Bhatt RK. The predictive role of color doppler sonography in evaluating hypoxia and acidosis in intrauterine growth restriction fetuses: correlation with arterial blood gas analysis. Int J Reprod Contracept Obstet Gynecol 2020;9:1119-23. 